\title{
Trends in cigarette pricing and purchasing patterns in a sample of US smokers: findings from the ITC US Surveys (2002-2011)
}

\author{
Monica E Cornelius, ${ }^{1,2}$ Pete Driezen, ${ }^{3}$ Andrew Hyland, ${ }^{4}$ Geoffrey T Fong, ${ }^{5,6,7}$ \\ Frank J Chaloupka, $8,9,10$ K Michael Cummings ${ }^{1,2}$
}

- Additional material is published online only. To view please visit the journal online (http://dx.doi.org/10.1136/ tobaccocontrol-2013-051376).

For numbered affiliations see end of article.

\section{Correspondence to} Dr Monica Cornelius, Postdoctoral Scholar, Medical University of South Carolina, Department of Psychiatry \& Behavioral Sciences, 68 President Street, BE 103, Cancer Control, Charleston, SC 29425, USA; mec24@musc.edu

Received 3 October 2013 Revised 10 April 2014 Accepted 13 May 2014 Published Online First 10 June 2014
CrossMark

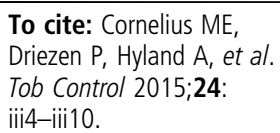

\section{ABSTRACT}

Objective This paper examines trends in cigarette prices and corresponding purchasing patterns over a 9year period and explores characteristics associated with the quantity and location of cigarettes purchased by adult smokers in the USA.

Methods The data for this paper come from a nationally representative longitudinal survey of 6669 adult smokers (18 years and older) who were recruited and surveyed between 2002 and 2011. Telephone interviews were conducted annually, and smokers were asked a series of questions about the location, quantity (ie, single vs multiple packs or cartons) and price paid for their most recent cigarette purchase. Generalised estimating equations were used to assess trends and model characteristics associated with cigarette purchasing behaviours.

Results Between 2002 and 2011, the reported purchase of cigarette cartons and the use of coupons declined while multipack purchases increased. Compared with those purchasing by single packs, those who purchased by multipacks and cartons saved an average of $\$ 0.53$ and $\$ 1.63$, respectively. Purchases in grocery and discount stores declined, while purchases in tobacco only outlets increased slightly. Female, older, white smokers were more likely to purchase cigarettes by the carton or in multipacks and in locations commonly associated with tax avoidance (ie, duty free shops, Indian reservations).

Conclusions As cigarette prices have risen, smokers have begun purchasing via multipacks instead of cartons. As carton sales have declined, purchases from grocery and discount stores have also declined, while an increasing number of smokers report low tax sources as their usual purchase location for cigarettes.

\section{INTRODUCTION}

Many key tobacco control policies are implemented in order to (1) reduce cigarette consumption among current smokers and (2) discourage tobacco consumption among non-smokers, especially youth. ${ }^{1}{ }^{2}$ The most effective way to achieve these goals is to increase the price of cigarettes. ${ }^{3}$ The higher the price of purchasing a pack of cigarettes, the less likely it is that people will buy and consume cigarettes. ${ }^{4}$

However, there are many factors that can disrupt the simple relationship between the price of cigarettes and consumption. For example, consumers can offset higher prices by purchasing cigarettes in bulk such as in cartons or in multipacks rather than as single packs. In addition, smokers can switch to lower priced cigarette brands, switch to brands offering price discounts and shop for cigarettes in locations where cigarettes are less expensive. ${ }^{5} 6$ Finally, smokers can respond to higher cigarette prices by reducing their daily intake of cigarettes or stop their cigarette consumption all together. While not all smokers will necessarily engage in priceminimising behaviours, the steady rise in cigarette prices coupled with increasing rates of unemployment, stagnant and/or declining wages, and higher household expenses for items like gasoline and food have combined over the past several years to make cigarettes less affordable. A recent article from the International Tobacco Control (ITC) United States Survey reported an increase in the use of discount cigarettes by US smokers after the 2009 increase of $\$ 0.61$ in the federal excise tax (FET) on cigarettes. ${ }^{7}$

Previous studies from the ITC Project have examined price-minimising behaviours in relationship to smoking cessation and smoker socioeconomic status using data from the USA, the UK, Canada and Australia. ${ }^{6}$ The present study examines trends in purchasing patterns in a group of US adult smokers surveyed annually between 2002 and 2011. During this time period, cigarette prices increased as a result of state and federal tax increases. In addition, cigarette manufacturers began to compete more directly on purchase price rather than imaged-based advertising due to restrictions in advertising. ${ }^{9}$

This paper extends the previous work by (1) examining trends in cigarette prices and typical quantity of cigarettes purchased (ie, single vs multiple packs or cartons), use of coupons and locations where cigarettes are typically purchased; (2) assessing characteristics related to bulk purchasing, coupon use and tax avoidance; and (3) observing how these activities coincide with changes in pricing and tax rates. Taken together, this information is used to evaluate the trends in, and the profile of smokers who use tactics to lower their cigarette costs in response to increased state and federal cigarette excise taxes over a 9-year period.

\section{METHODS}

\section{Study design and sample}

This paper uses data from a nationally representative longitudinal survey of 6669 adult current smokers who were recruited and surveyed between 2002 and 2011 for the ITC US Survey. Standardised telephone interviews were conducted annually. At initial enrolment, survey participants 
included adult smokers (18 years of age and older) who reported that they had smoked at least 100 cigarettes in their lifetime and had smoked at least 1 cigarette in the past 30 days. Probability sampling methods were used to recruit the sample using random-digit dialling. If multiple adult smokers were present in the home, the next-birthday method was used to select the respondent. Survey participants who were lost to follow-up in subsequent survey waves were replenished using the same procedures as the original recruitment. This process was used to maintain a sample size of 1500-2000 participants per wave. The average attrition rate was $35 \%$ for each survey wave. Further details of the survey methodology have been documented elsewhere. ${ }^{10}$

\section{Measures}

Quantity of cigarettes purchased

Participants who reported smoking factory-made cigarettes were asked whether they bought cigarettes by carton, pack or by individual cigarettes out of a pack on their last purchase occasion. A standard carton of cigarettes contains 10 individual packs of 20 cigarettes each. For the purposes of this study, multipack purchases were defined as purchases of $>1$ and $<10$ individual packs of cigarettes. Bulk purchases were indicated by purchases of more than a single package of cigarettes (ie, either multiple packs or cartons). Previous studies have described multipack sales in terms of manufacturers' 'buy one get one free' promotions; ${ }^{11}$ however, multipacks do not need to be part of a special price promotion offer.

\section{Purchasing locations}

Participants were asked where they bought their cigarettes on their last purchase occasion. Purchase locations were selected from a predefined list that included the following categories: (1) convenience store/gas station; (2) grocery, discount or drug store; (3) tobacco outlets, smoke shops; (4) Indian reservation; (5) liquor store; (6) outside of the state; (7) duty-free; (8) outside of the country; (9) from a toll-free number; (10) from the internet and (11) other. Text responses entered under 'other' were either added to the appropriate existing category (where appropriate) or left as 'other'. Among purchase locations, a purchase made at an Indian reservation, outside of one's home state, duty-free, from a toll-free number, outside of the country or from the internet was designated as a location with the potential for tax avoidance (low tax location).

\section{Use of coupon/special price discounts}

Participants were also asked whether they used any coupons or received special discounts on their last purchase of cigarettes. Those responding 'yes' were considered positive for coupon/discount use.

\section{Purchase price}

Participants were asked to report the amount they paid for the cigarettes they purchased last. Self-reported purchase prices were standardised to the cost paid for a single pack of 20 cigarettes and adjusted to reflect the price paid in 2011 US $\$ .^{12}$

\section{Data and statistical analysis}

Descriptive statistics were used to characterise trends in per pack cigarette prices and purchasing habits between 2002 and 2011. Generalised estimating equations (GEE) were used to (1) test for trends in bulk purchasing, coupon/special discount usage and purchase locations; (2) estimate adjusted wave specific prevalence rates for each of the outcomes and (3) model the characteristics of participants associated with bulk purchasing and tax avoidance. ${ }^{13}$ Because all of the outcomes of interest were dichotomous, a repeated measures binomial distribution with the logit link was used for the regression models. An unstructured correlation structure was used to account for correlation among repeated measures on subjects. In cases where the model did not converge or the software indicated that a simpler correlation structure was more appropriate, an exchangeable correlation structure was used. We tested for linear trends in outcomes from 2002 to 2011. We also tested for differences in outcomes between the survey waves conducted prior to (wave 7, 2008-2009) and after (wave 8, 20102011) the $\$ 0.61$ increase in the FET on 1 April 2009. Variables examined as predictors of bulk purchasing and tax avoidance included the participant's gender, age, race, household income (ie, defined as low: $\leq \$ 29$ 999; medium: $\$ 30000-\$ 59999$; or high: $\geq \$ 60000$ ), education (ie, defined as low: $\leq$ high school; moderate: some college/tech/trade school, no degree; high: university degree or higher), level of nicotine dependence (ie, measured by heaviness of smoking index [scored 0-6] and categorised as low: $\leq 4$ or high: $>4$ ), intention to quit smoking, geographic region of the USA (ie, northeast, south, midwest or west) and brand value type (ie, premium vs discount). Brand value type was determined using representations from the manufacturers and has been described elsewhere. ${ }^{7}$ Results were weighted to reflect the population composition of US adult smokers, and all analyses were performed using SAS V.9.3. ${ }^{14}$

\section{RESULTS}

\section{Sample characteristics}

Table 1 shows the demographic characteristics of the study sample. In general, the sample is representative of the adult smoking population in the USA, with a slight overrepresentation of women and smokers between 40 and 54 years of age. While $44.5 \%$ of participants completed only a single survey, $55.5 \%$ completed two or more surveys.

\section{Price paid per pack and purchase quantity}

Figure 1 illustrates the prevalence of carton, multipack and single-pack purchases along with the average price paid for cigarettes from each survey wave from 2002 to 2011 . The sharpest increase in the price paid for a package of cigarettes was observed between 2009 and 2011, corresponding to the $\$ 0.61$ increase in the FET on cigarettes. Over the entire study period, most smokers purchased by either single or multipack rather than by the carton, although the prevalence of carton purchases was the highest of the three categories. However, carton purchases began to decrease after 2007. Comparing the purchase price paid for cartons to single packs, the average savings per pack was $\$ 1.63$ for carton purchases, although there were fluctuations in savings over the survey period. On average, purchasing cigarettes by multipacks saved $\$ 0.53$ on average than purchasing a single pack. No statistically significant linear trends were detected in carton purchases $(35.6 \%$ to $33.3 \% ; \mathrm{p}=0.36)$ or single-pack purchases $(35.1 \%$ to $34.5 \%, \mathrm{p}=0.40)$ while a slight increase was observed in multipack purchases $(25.6 \%$ to $28.6 \% ; \mathrm{p}<0.05)$ from 2002 to 2011. Across the different survey waves, the prevalence of respondents switching from cartons to multipacks between successive waves ranged from 3.7 to $7.2 \%$, while the prevalence of respondents switching from single packs to multipacks ranged from 4.3 to $6.5 \%$ from 2002 to 2011. No statistically significant linear trends over time were detected. The prevalence of switching from multipacks to single 
Table 1 Baseline demographic characteristics of ITC US sample $(\mathrm{N}=6669)$

\begin{tabular}{|c|c|c|}
\hline Characteristic & $\mathrm{N}$ & Per cent \\
\hline \multicolumn{3}{|l|}{ Sex } \\
\hline Male & 3032 & (45.5) \\
\hline Female & 3637 & $(54.5)$ \\
\hline \multicolumn{3}{|l|}{ Age } \\
\hline $18-24$ & 749 & $(11.2)$ \\
\hline $25-39$ & 1710 & (25.6) \\
\hline $40-54$ & 2436 & (36.5) \\
\hline $55+$ & 1774 & $(26.6)$ \\
\hline \multicolumn{3}{|l|}{ Race } \\
\hline Black & 668 & (10.1) \\
\hline Other & 813 & $(12.2)$ \\
\hline White & 5163 & $(77.7)$ \\
\hline \multicolumn{3}{|l|}{ Education* } \\
\hline Low & 3037 & (45.6) \\
\hline Moderate & 2547 & (38.2) \\
\hline High & 1073 & $(16.1)$ \\
\hline No answer & 12 & $(0.2)$ \\
\hline \multicolumn{3}{|l|}{ Incomet } \\
\hline Low & 2454 & $(36.8)$ \\
\hline Moderate & 2182 & (32.7) \\
\hline High & 1542 & (23.1) \\
\hline No answer & 491 & $(7.4)$ \\
\hline \multicolumn{3}{|c|}{ \# of participants recruited at each survey wave } \\
\hline Wave 1 & 2140 & $(32.1)$ \\
\hline Wave 2 & 684 & $(10.3)$ \\
\hline Wave 3 & 889 & $(13.3)$ \\
\hline Wave 4 & 742 & $(11.1)$ \\
\hline Wave 5 & 745 & $(11.1)$ \\
\hline Wave 6 & 711 & $(10.7)$ \\
\hline Wave 7 & 382 & (5.7) \\
\hline Wave 8 & 376 & (5.6) \\
\hline \multicolumn{3}{|c|}{ \# Surveys completed by respondents } \\
\hline 1 & 2969 & $(44.5)$ \\
\hline 2 & 1519 & (22.8) \\
\hline 3 & 876 & $(13.1)$ \\
\hline 4 & 498 & $(7.5)$ \\
\hline 5 & 319 & $(4.8)$ \\
\hline 6 & 212 & $(3.2)$ \\
\hline 7 & 124 & (1.9) \\
\hline 8 & 152 & $(2.3)$ \\
\hline
\end{tabular}

packs declined $(5.1 \%$ to $1.9 \%, \mathrm{p}<0.001)$. Switching from multipacks to cartons also declined $(3.6 \%$ to $1.3 \%, \mathrm{p}<0.01)$.

\section{Coupon use and special discount trends}

As shown in figure 2, the reported use of coupon/special discount was relatively low from 2002 to 2011. The use of coupons and price discounts declined after 2005 when multipack purchasing began to increase, corresponding to the decline in manufacturer expenditures for coupons. ${ }^{9}$

\section{Cigarette purchase location trends}

Figure 3 depicts the locations of cigarette purchases over the eight survey waves. (Data values for figure 3 are available in

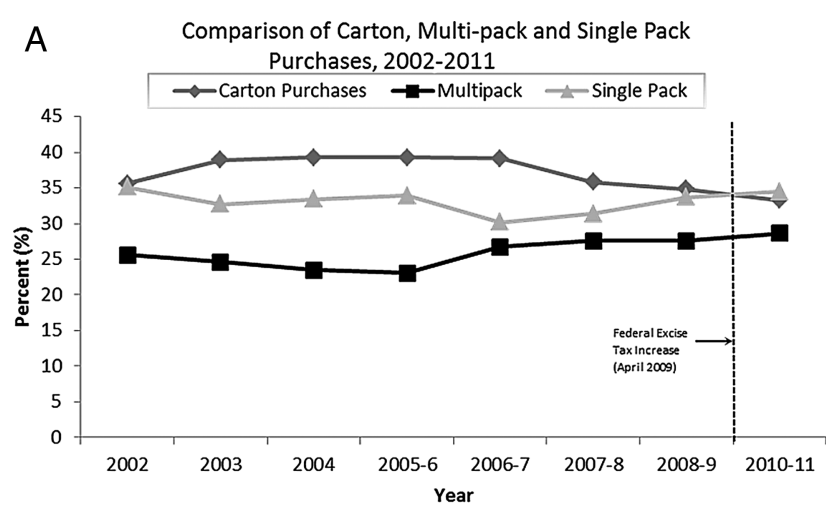

B Comparison of Pack Prices for Carton, Multipack and

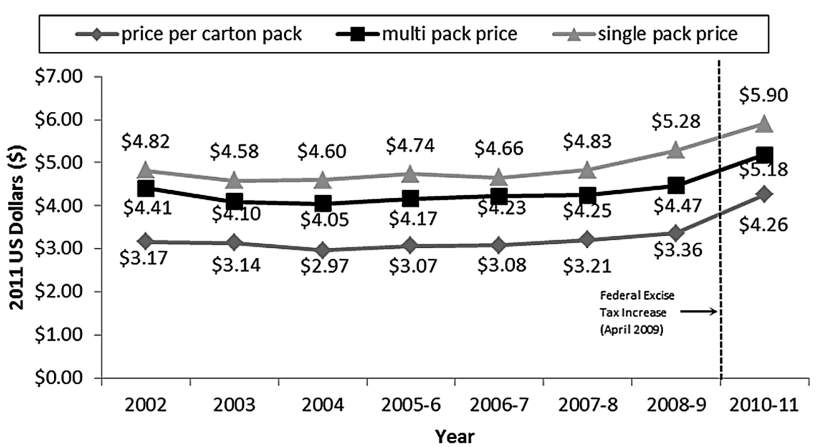

Figure 1 Trends in carton and pack purchases with average price paid per pack, 2002-2011. All percentages are adjusted for age, sex, time-in-sample, wave, and daily smoking only. Prices are additionally adjusted for income, education, region, brand type, and low tax purchase location.

online supplementary appendix 1.) Convenience stores and gas stations were the most frequently reported locations for cigarette purchases in all survey waves, followed by grocery and discount stores, and tobacco outlets (figure 3A). Purchases from convenience stores/gas stations were fairly stable over the survey period from 2002 to $2011(56.6 \%$ to $59.7 \%$; $\mathrm{p}=0.08)$. Decreases in purchases in grocery, discount and drug stores $(19.6 \%$ to $12 \% ; \mathrm{p}<0.01)$ and 'other' locations $(6.9 \%$ to $4.0 \%$; $\mathrm{p}<0.01)$ were detected from 2002 to 2011 . The use of tobacco outlets for purchases increased over this time period from $12.3 \%$ to $17.1 \%(\mathrm{p}<0.01)$. Purchases from low tax locations

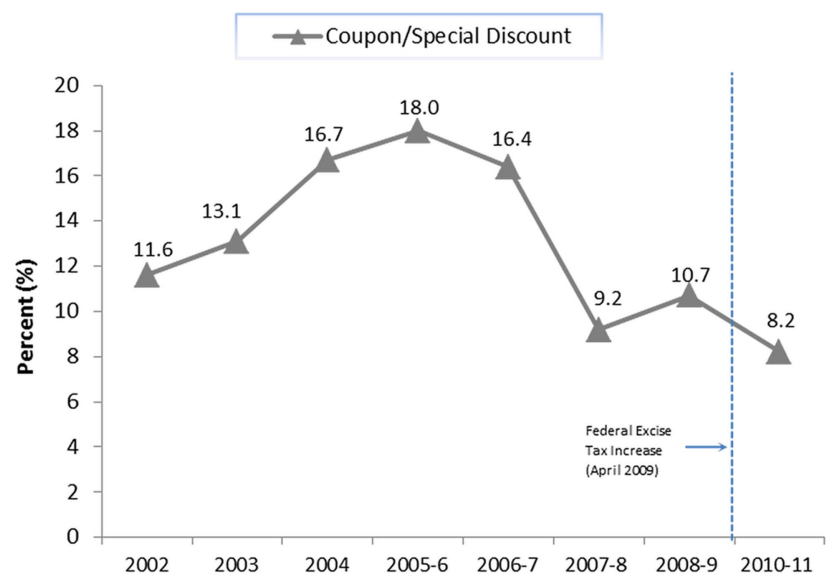

Figure 2 Coupon/special discount use, 2002-2011. All percentages are adjusted for age, sex, time-in-sample, wave, and daily smoking only. 


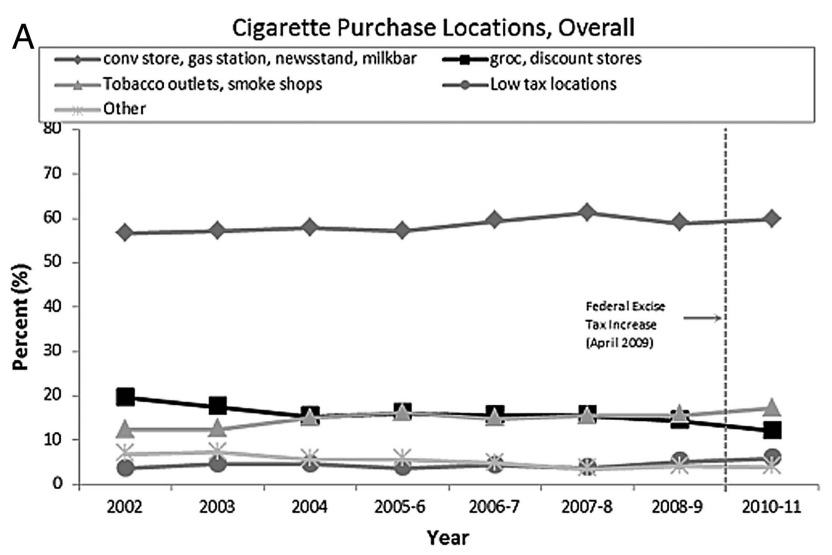

B
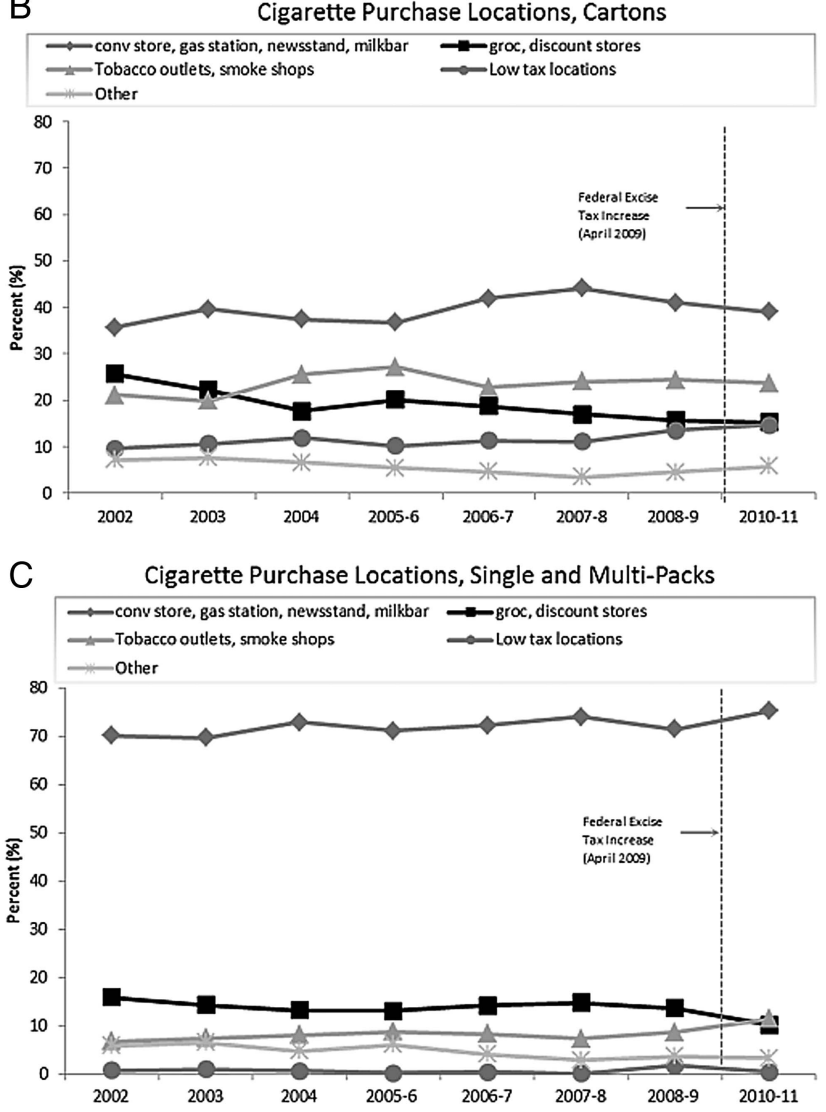

Figure 3 Locations of purchase overall and by bulk purchase type. All percentages are adjusted for age, sex, time-in-sample, wave, and daily smoking only. 'Other' locations include: bar/restaurant, casino; liquor store; military commissary; vending machine and all others.

rose from $3.6 \%$ in 2002 to $5.9 \%$ in 2011 , although this result was not statistically significant $(\mathrm{p}=0.15)$. This trend was likely due in part to purchasing on Indian reservations, which rose from $2.2 \%$ to $3.6 \%$ from 2002 to 2011 ( $p=0.04$ ).

Cartons were purchased most often from convenience stores and gas stations; grocery, discount and drug stores; and tobacco outlets (figure $3 \mathrm{~B}$ ). Purchases of cartons decreased in grocery and discount stores $(25.7 \%$ to $15.3 \% ; \mathrm{p}<0.01)$ and also in 'other' locations $(7.2 \%$ to $5.8 \%$; $=0.03)$ from 2002 to 2011. Carton purchases from Indian reservations rose from $5.3 \%$ to $10.2 \%(p<0.01)$ over the survey period. The majority of single and multipack purchases were made at convenience stores and gas stations (figure 3C). The prevalence of single and multiple pack purchases decreased in 'other' locations from $5.9 \%$ to $3.3 \%(\mathrm{p}<0.01)$ over the study period.
Use of bulk purchasing, coupons or tax avoidance has been highly consistent over the survey period (data not shown). Overall, $67-72 \%$ of smokers in each wave used either bulk purchasing, coupons or tax avoidance behaviours from 2002 to 2011.

\section{Bulk purchasing and tax avoidance characteristics}

Table 2 depicts factors associated with carton purchases, multipack purchases and tax avoidance. All outcomes were associated with female gender, older age (age $\geq 25$ years), White race, greater nicotine addiction, use of discount cigarettes and intention to quit smoking. Additionally, carton purchasing was associated with high income and daily smoking. Carton purchasing was more likely in the southern region and less likely in the northeastern region when compared with the western region. Multipack purchases (compared with single-pack purchase) were additionally associated with moderate income (compared with high income), and living in the midwestern and southern regions of the USA and daily smoking. Tax avoidance was more likely in the northeastern region and less likely in the midwestern and southern regions when compared with the western region. Bulk purchasing and tax avoidance was less likely among smokers intending to quit. Controlling for age, sex, race, nicotine addiction, smoking status, intention to quit smoking, brand value, income, education, region, time-in-sample and wave we did not observe a statistically significant change in bulk purchasing and tax avoidance before and after the implementation of the FET in 2009 .

\section{DISCUSSION}

The average price paid for a single package of cigarettes in the USA rose steadily from 2002 to 2011, with a large increase observed after the 2009 FET increase. On a per pack basis, the price was substantially lower for purchasing by the carton than by the pack. The price differential between carton and pack sales was fairly stable over the entire study period. Despite the relative per pack price advantage of purchasing cigarettes by the carton, smokers are increasingly choosing to purchase their cigarettes by the pack instead of by the carton. A number of factors may have contributed to this trend. Additional analyses of these data show that many smokers appear to be smoking fewer cigarettes per day, decreasing from 19 in 2002 to 17 in 2011. This is likely in response to higher cigarette prices, less disposable income and/or increasing restrictions on when and where they are permitted to smoke. Additionally, it is possible that some smokers may find the high entry cost of a carton of cigarettes too steep, whereas the perceived lower daily per pack price seems more affordable, especially if they are intending to reduce their smoking and/or stop smoking. Additional analyses of the data found that those who were intending to quit had a $20-54 \%$ reduced odds of bulk purchasing or purchasing from a low tax location.

Results from this study found that most smokers purchased either by single or multipack rather than by the carton, and this is consistent with other studies. ${ }^{5} 1516$ The reported use of coupons and price discounts was not all that common among the smokers we surveyed and peaked at about 18\% in 2005 . Coupon use began to decline in the later years of the survey, coinciding with a decline in manufacturer expenditures for coupon promotions. ${ }^{9}$ Multipack purchasing increased noticeably after 2005. Smokers who previously reduced the price of their cigarette purchases through coupons and price discounts now had the option of reducing costs through purchasing multipacks. These trends may be reflective of changes in price promotions 
Table 2 Characteristics associated with bulk purchasing and tax avoidance

\begin{tabular}{|c|c|c|c|c|c|c|}
\hline \multirow[b]{2}{*}{ Variables } & \multicolumn{2}{|c|}{$\begin{array}{l}\text { Model } 1 \text { carton purchases } \\
\text { versus non carton purchases } \\
(\mathrm{N}=6206)\end{array}$} & \multicolumn{2}{|c|}{$\begin{array}{l}\text { Model } 2 \text { multipack versus } \\
\text { single pack purchases } \\
(\mathrm{N}=4109)\end{array}$} & \multicolumn{2}{|c|}{$\begin{array}{l}\text { Model } 3 \text { tax avoidance } \\
\text { location versus other } \\
\text { purchase location }(\mathrm{N}=6246)\end{array}$} \\
\hline & OR & $95 \% \mathrm{Cl}$ & OR & $95 \% \mathrm{Cl}$ & OR & $95 \% \mathrm{Cl}$ \\
\hline \multicolumn{7}{|l|}{ Sex } \\
\hline Females vs males & 1.36 & (1.21 to 1.53$)$ & 1.33 & (1.17 to 1.52 ) & 1.51 & (1.18 to 1.92$)$ \\
\hline \multicolumn{7}{|l|}{ Age } \\
\hline $25-39$ vs $18-24$ & 2.13 & (1.65 to 2.76 ) & 1.70 & (1.35 to 2.14 ) & 1.45 & (0.75 to 2.80 ) \\
\hline $40-54$ vs $18-24$ & 3.85 & (3.00 to 4.95 ) & 2.11 & (1.68 to 2.63 ) & 2.38 & (1.27 to 4.45$)$ \\
\hline $55-\max$ vs $18-24$ & 7.59 & (5.86 to 9.84$)$ & 2.44 & (1.89 to 3.15 ) & 2.97 & (1.55 to 5.66$)$ \\
\hline \multicolumn{7}{|l|}{ Race } \\
\hline Other vs white & 0.60 & (0.49 to 0.73 ) & 0.75 & (0.61 to 0.93$)$ & 0.77 & (0.53 to 1.11 ) \\
\hline Black vs white & 0.23 & $(0.17$ to 0.30$)$ & 0.40 & ( 0.32 to 0.51$)$ & 0.12 & (0.04 to 0.32$)$ \\
\hline \multicolumn{7}{|l|}{ Incomet } \\
\hline Low vs high & 0.66 & (0.56 to 0.76 ) & 1.13 & (0.94 to 1.36$)$ & 1.13 & (0.84 to 1.52 ) \\
\hline Middle vs high & 0.79 & ( 0.69 to 0.91$)$ & 1.20 & (1.01 to 1.43 ) & 0.95 & (0.71 to 1.28 ) \\
\hline No answer vs high & 0.94 & (0.74 to 1.20$)$ & 1.06 & (0.77 to 1.48$)$ & 0.73 & (0.41 to 1.28 ) \\
\hline \multicolumn{7}{|l|}{ Education $\ddagger$} \\
\hline Low vs high & 0.99 & (0.84 to 1.17 ) & 0.87 & (0.70 to 1.07 ) & 0.94 & (0.67 to 1.33 ) \\
\hline Middle vs high & 0.97 & (0.85 to 1.11$)$ & 1.02 & (0.88 to 1.19 ) & 0.71 & (0.54 to 0.93 ) \\
\hline \multicolumn{7}{|l|}{ Nicotine dependence§ } \\
\hline$\geq 4$ vs $<4$ & 1.45 & (1.32 to 1.60$)$ & 2.06 & (1.74 to 2.44 ) & 1.44 & (1.19 to 1.75$)$ \\
\hline \multicolumn{7}{|l|}{ Smoking } \\
\hline Daily vs non-daily & 2.76 & (2.16 to 3.52 ) & 2.19 & (1.71 to 2.81 ) & 1.63 & (0.85 to 3.14$)$ \\
\hline \multicolumn{7}{|l|}{ Brand value } \\
\hline Premium vs discount & 0.58 & (0.51 to 0.65$)$ & 0.74 & (0.63 to 0.86$)$ & 0.50 & (0.39 to 0.63$)$ \\
\hline \multicolumn{7}{|l|}{ Region } \\
\hline Midwest vs west & 0.93 & (0.77 to 1.11$)$ & 1.40 & (1.15 to 1.71$)$ & 0.29 & (0.20 to 0.42$)$ \\
\hline Northeast vs west & 0.73 & ( 0.60 to 0.88$)$ & 0.95 & (0.77 to 1.18$)$ & 1.93 & (1.46 to 2.55$)$ \\
\hline South vs west & 1.25 & (1.06 to 1.48$)$ & 1.41 & (1.16 to 1.71$)$ & 0.18 & $(0.12$ to 0.26$)$ \\
\hline \multicolumn{7}{|l|}{ Quit intentions } \\
\hline Beyond 6 months vs not quitting & 0.79 & (0.71 to 0.87$)$ & 0.80 & (0.68 to 0.94$)$ & 0.68 & (0.55 to 0.84$)$ \\
\hline $1-6$ months vs not quitting & 0.57 & ( 0.50 to 0.64$)$ & 0.69 & (0.58 to 0.82$)$ & 0.69 & (0.54 to 0.90$)$ \\
\hline Within next month vs not quitting & 0.46 & ( 0.39 to 0.55$)$ & 0.51 & (0.41 to 0.64$)$ & 0.61 & (0.42 to 0.89$)$ \\
\hline \multicolumn{7}{|l|}{ Wave } \\
\hline Wave 1 vs 8 & 1.02 & (0.80 to 1.30$)$ & 0.92 & (0.68 to 1.25$)$ & 0.61 & (0.38 to 0.99$)$ \\
\hline Wave 2 vs 8 & 1.16 & (0.92 to 1.47$)$ & 0.98 & (0.73 to 1.32 ) & 0.71 & (0.45 to 1.11 ) \\
\hline Wave 3 vs 8 & 1.19 & (0.95 to 1.48 ) & 0.90 & (0.67 to 1.20 ) & 0.72 & (0.47 to 1.11 ) \\
\hline Wave 4 vs 8 & 1.25 & (1.01 to 1.54 ) & 0.91 & (0.68 to 1.21 ) & 0.61 & (0.40 to 0.92$)$ \\
\hline Wave 5 vs 8 & 1.18 & (0.97 to 1.44 ) & 1.17 & (0.89 to 1.55 ) & 0.71 & (0.48 to 1.07 ) \\
\hline Wave 6 vs 8 & 1.04 & (0.87 to 1.25 ) & 1.09 & (0.82 to 1.45 ) & 0.61 & (0.41 to 0.89 ) \\
\hline Wave 7 vs 8 & 0.99 & (0.84 to 1.18 ) & 1.02 & (0.76 to 1.36 ) & 0.91 & (0.64 to 1.28 ) \\
\hline
\end{tabular}

offered by cigarette manufacturers in response to the slowing US economy that negatively impacted the affordability of cigarettes. $^{6} 17$ Multipacks represent an affordable option, with pricing between that of cartons and single packs. Noting price fluctuations and regional variation over the survey period, those purchasing by cartons spent an average of $\$ 51.02$ per purchase occasion compared with $\$ 13.48$ for multipacks and $\$ 5.65$ for single packs.

Advertising and price promotions, particularly those at the point of sale (POS) in convenience stores and gas stations (ie, multipack discounts, coupons, etc), constituted a significant proportion of cigarette manufacturer expenditures during the time period of this study and are often implemented to strategically offset impending tax increases among current and potential smokers. ${ }^{4} 18 \quad 19$ Since pack purchases were overwhelmingly more likely to be made at these locations, advertising promotions at the POS for multipack purchases could help to explain why multipack purchases increased while carton purchases declined from 2006 to 2011.

Examination of characteristics of smokers using bulk purchasing and tax avoidance yielded similar results in that choice of discount brand was associated with bulk purchasing and tax avoidance. This may indicate that addicted smokers who exhibit these tactics are also likely to use discount cigarette brands at some point. Previous studies have shown that older, heavier smokers were more likely to switch to discount brands, ${ }^{7}$ while 
this analysis has found that older smokers were more likely to use bulk purchasing and tax avoidance methods. Overall, white, female, older and more addicted smokers were more likely to purchase cigarettes in high quantities and try to avoid taxes. The fact that female smokers were more likely to purchase in high quantities and try to avoid taxes is consistent with the study by Licht et $a l^{8}{ }^{8}$ which uses ITC data from four countries. As well, studies using non-ITC data have found that female smokers were more likely to purchase in 'less expensive venues' or from Indian reservations, and also that female smokers were more likely to use promotional offers 'every time they see one'. ${ }^{20-22}$ An article by Pesko et $a l^{16}$ reported that female smokers were more likely to purchase cartons, while a study by Mecredy et $a l^{23}$ found that a greater percentage of females purchased contraband tobacco regularly.

A distinguishing characteristic of carton purchasers was higher income since greater income is needed for this method of costcutting; this result is consistent with those from studies by Licht et al. ${ }^{8}$ Tax avoidance was more likely in areas where cigarette taxes (in addition to the cost of living) were highest (ie, west and northeast regions). Additionally, the higher total cost of cigarettes, in addition to the close proximity of Indian reservations, may also explain this occurrence. Previous research has indicated that price promotions are highest where tobacco control policies are strongest (ie, west and northeast). ${ }^{18}$ Work by Harding et $a l^{24}$ has also indicated that the impact of increased tax burden experienced by consumers differs by state tax rate, which, in turn, influences the extent to which consumers seek out strategies to minimise cigarette costs. Results from this study indicate that income is not associated with tax avoidance, while moderate income was associated with multipack purchases (compared with high income). Previous studies have found that price-sensitive smokers were more likely to take advantage of price promotions offered at the time of purchase. ${ }^{45}$ Licht $e t$ al ${ }^{8}$ also reported that smokers from lower SES groups were less likely to travel to other, cheaper venues for purchases. This may be due in part to an inability to travel to other, cheaper venues for purchases. Although multipack purchasing was not associated with low income, multipack purchases may still represent a more affordable option to moderate-income smokers. Using our definition of low income, it may be that multipacks, like cartons, remain unaffordable to low-income smokers.

Results do not indicate that the federal tax increase resulted in a statistically significant increase in bulk purchasing, tax avoidance or coupon use between waves 7 and 8 (when the FET increase occurred); however, the price differential between those who did and those who did not use at least one of the strategies for price minimisation was greatest after wave 7 . As well, some participants in wave 7 were surveyed after April $2009(323 / 1763$ or $\approx 18.3 \%)$, indicating that this measure of differences from wave 7 to 8 may be an underestimate of the differences. In order to more accurately isolate the effects of the FET, calendar year and month was controlled for and differences in outcomes before and after the FET increase were assessed, controlling for time-in-sample, sex, age, wave and daily smoking. We found that the FET tax increase was associated with decreased odds of purchasing by the carton $(\mathrm{OR}=0.80 ; \mathrm{p}<0.01)$ and increased odds of purchasing at low tax locations $(\mathrm{OR}=1.43 ; \mathrm{p}=0.03)$.

This should be interpreted carefully because other explanations could exist. First, consistent price promotions in the years leading up to the tax increase may have minimised the impact in such a way that a sudden, large increase in cost from the federal taxation was not experienced, thus maintaining prior purchase habits, particularly among those purchasing by multipacks. Price reduction by bulk purchasing appears to be a consistent occurrence, irrespective of changes in tax policies for cigarettes. Second, the weakened economy during this time period could have influenced purchase behaviour.

Results from this study revealed that $4-7 \%$ of respondents switched from cartons to multipacks and also from single packs to multipacks between successive waves over the 2002 to 2011 period. This may indicate not only reduced smoking among previous carton purchasers, but also increased smoking among those who typically purchased by single packs, due to the increased volume of cigarettes on hand, effectively offsetting the benefits of cigarette price increases. This may indicate that multipack purchase discounts enable reductions in smoking frequency by heavy smokers to be offset by increases in smoking by moderate to light smokers.

While these data report valuable information regarding behaviours surrounding price increases, there are limitations. Our analysis is limited to the last purchase of cigarettes, rather than the usual purchase quantity, which could result in some misclassification. As well, multipack purchases do not necessarily indicate a multipack discount. In this definition, multipack purchases may or may not always represent 'buy one get one free' price promotions that are reported to the Federal Trade Commission. However, those who purchased in this manner did save more than those who purchased single packs, on average. Because the questionnaire item asks about coupons and special discounts simultaneously, we were unable to determine whether some smokers may have interpreted 'buy-one-get-one free' as a 'special discount.' As a result, we were unable to isolate multipack discounts from coupon use, and therefore could not adjust per pack average price without the possibility of excluding multipack discounts. Nonetheless, a sensitivity analysis revealed that exclusion of all coupon/discount purchases did not affect estimates of price or prevalence among carton, multipack and single-pack purchases. Next, we only observed small magnitudes of differences in our outcomes of interest. Despite this, small per cent differences may often equate to large numbers of affected lives at the population level. As well, we did not assess purchases of single/ loose cigarettes because too few participants indicated purchasing in this quantity. Additionally, small sample sizes of individual tax avoidance methods (except for Indian reservations) prevented us from being able to assess characteristics related to specific tax avoidance methods. It is possible that characteristics may differ by specific tax avoidance methods as found by Licht et al. ${ }^{8}$

Cigarette consumption is reduced by $2.5-5 \%$ when prices increase $10 \%$; however, consumers' uses of strategies to lessen the price they pay reduce this impact. ${ }^{3} 2526$ We found that these price reduction strategies have remained high over the last 9 years in the USA, with differing strategies dominating at different times. Carton, multipack purchasing and coupons have long been an effective method for smokers to save money, with carton purchases more likely among those of higher SES. Multipack discounts and coupons serve as an effective method for all smokers (especially those of lower SES) to reduce their cigarette costs. Tax avoidance and coupon use were used less often for price reduction than bulk purchasing.

Results from this study support the notion that price promotions can induce cost savings, which can, in turn, decrease motivation for quitting smoking. The fact that over two-thirds of participants at each of the eight survey waves over 9 years reported using bulk purchasing, coupons, or tax avoidance demonstrates the very widespread availability of cost saving measures offered by the cigarette manufacturers. Multipack 
purchasing, in particular, may especially lower motivation for quitting smoking. Tobacco manufacturers have used couponing and multipack discounts as a mechanism for offsetting the immediate impact of tax increases, resulting in a smaller reduction in cigarette consumption. ${ }^{4}$ Using these measures over time periods both prior to and after a tax increase circumvents the perception of a dramatic price increase that might prompt more smokers to think about quitting. Moreover, price promotions simply increase the affordability of smoking, thereby reducing smoking cessation. Standardising the quantity of cigarettes sold to packs and/or carton sizes only and establishing minimum pricing laws would help limit the manufacturers' ability to manipulate cigarette affordability, which would help strengthen the impact of price increases on smoking cessation.

\section{What this paper adds}

- This paper examines trends in cigarette prices and corresponding purchasing patterns from 2002 to 2011 and explores characteristics associated with the typical quantity of cigarettes purchased (ie, single vs multiple packs or cartons) and location where cigarettes are typically purchased by adult smokers in the USA.

- As cigarette prices have risen, consumers have found different ways to circumvent the increased costs of purchasing cigarettes. Over two-thirds of respondents reported using bulk purchasing, coupons and/or tax avoidance to lower the purchase costs of cigarettes. Despite the relative per pack price advantage of purchasing cigarettes by the carton instead by the pack, smokers increasingly chose to purchase their cigarettes by the pack instead of by the carton. A number of factors may have contributed to this trend including the fact that many smokers are smoking fewer cigarettes per day and/or increasing restrictions on when and where smokers are permitted to light up. It appears that multipacks are beginning to replace 10-pack carton sales as the primary means of bulk purchasing.

\footnotetext{
Author affiliations

${ }^{1}$ Department of Psychiatry \& Behavioral Sciences, Medical University of South Carolina, Charleston, South Carolina, USA

${ }^{2}$ Hollings Cancer Center, Medical University of South Carolina, Charleston, South Carolina, USA

${ }^{3}$ Department of Psychology, University of Waterloo, Waterloo, Ontario, Canada ${ }^{4}$ Department of Health Behavior, Roswell Park Cancer Institute, Buffalo, New York, USA

${ }^{5}$ Department of Psychology, University of Waterloo, Waterloo, Ontario, Canada ${ }^{6}$ Ontario Institute for Cancer Research, Toronto, Ontario, Canada

${ }^{7}$ School of Public Health and Health Systems, University of Waterloo, Ontario, Canada

${ }^{8}$ Health Policy Center, Institute for Health Research and Policy, University of Illinois at Chicago, Chicago, Illinois, USA

${ }^{9}$ Department of Economics, University of Illinois at Chicago, Chicago, Illinois, USA

${ }^{10}$ WHO Collaborating Centre on the Economics of Tobacco and Tobacco Control
}

Contributors MEC, PD, KMC and FJC contributed to data analysis and interpretation, and in drafting the manuscript and revising critically for important intellectual content. GTF, KMC and AH contributed to the study conception and survey design, and in drafting the manuscript and revising it critically for intellectual content. All authors have read and approved the final manuscript.

Funding The ITC US Project was supported by grants from the US National Cancer Institute at the National Institutes of Health (R01 CA100362, R01 CA125116, P01 CA138389, R25 CA113951): the Roswell Park Transdisciplinary Tobacco Use Research Center (P50 CA111236); Robert Wood Johnson Foundation (045734);
Canadian Institutes for Health Research (57897, 79551 and 115016). Additional support was provided to Geoffrey T. Fong from a Senior Investigator Award from the Ontario Institute for Cancer Research and a Prevention Scientist Award from the Canadian Cancer Society Research Institute.

Competing interests KMC has served in the past and continues to serve as a paid expert witness for plaintiffs in litigation against the tobacco industry.

Ethics approval The ITC US Surveys were cleared for ethics by Research Ethics Boards or International Review Boards at the University of Waterloo (Canada), Roswell Park Cancer Institute (USA) and Medical University of South Carolina (USA).

Provenance and peer review Not commissioned; externally peer reviewed.

\section{REFERENCES}

1 World Health Organization. WHO framework convention on tobacco control. Geneva, Switzerland: WHO Document Production Services, 2005.

2 Centers for Disease Control and Prevention. Tips from former smokers: Campaign Overview. Retrieved from: http://www.cdc.gov/tobacco/campaign/tips/about/ campaign-overview.html 2013.

3 Chaloupka FJ, Straif K, Leon ME. Effectiveness of tax and price policies in tobacco control. Tob Control 2011;20:235-8.

4 Chaloupka FJ, Cummings KM, Morley C, et al. Tax, price and cigarette smoking: evidence from the tobacco documents and implications for tobacco company marketing strategies. Tob Control 2002;11(Suppl 1):i62-72.

5 Choi K, Hennrikus D, Forster J, et al. Use of price-minimizing strategies by smokers and their effects on subsequent smoking behaviors. Nicotine \& Tobacco Research 2011;14:864-70.

6 Licht AS, Hyland AJ, O'Connor RJ, et al. How do price minimizing behaviors impact smoking cessation? Findings from the International Tobacco Control (ITC) Four Country Survey. Int J Environ Res Public Health 2011;8:1671-91.

7 Cornelius ME, Driezen P, Fong GT, et al. Trends in use of premium and discount cigarette brands: findings from the ITC US Surveys (2002-2011). Tob Control 2014;23:i48-i53.

8 Licht AS, Hyland AJ, O'Connor RJ, et al. Socio-economic variation in price minimizing behaviors: findings from the International Tobacco Control (ITC) Four Country Survey. Int J Environ Res Public Health 2011;8:234-52.

9 Federal Trade Commission. Federal Trade Commission Cigarette Reports for Years 2002-2010. 2013. http://www.ftc.gov/reports/index.shtm

10 Thompson ME, Fong GT, Hammond D, et al. Methods of the International Tobacco Control (ITC) Four Country Survey. Tob Control 2006;15(suppl 3):iii12-18.

11 Tauras JA, Peck RM, Chaloupka FJ. The role of retail prices and promotions in determining cigarette brand market shares. Rev Ind Organ 2006;28:253-84.

12 Adjusting prices for inflation and creating price indices: FEWS NET markets guidance, No 3. Washington, DC: Famine Early Warning Systems Network, United States Agency International Development. 2009.

13 Thompson ME, Boudreau C, Driezen P. Incorporating time-in-sample in longitudinal survey models. Statistics Canada International Symposium Series 2005: Methodological Challenges for Future Needs. Ottawa, ON, 2005.

14 SAS Institute Inc. SAS Version 9.3Cary, NC, 2011.

15 DeCicca P, Kenkel D, Liu F. Who pays cigarette taxes? The impact of consumer price search. Rev Econ Stat 2012;95:516-29.

16 Pesko MF, Kruger J, Hyland A. Cigarette price minimization strategies used by adults. Am J Public Health 2012;102:e19-21.

17 Loomis BR, Farrelly MC, Mann NH. The association of retail promotions for cigarettes with the Master Settlement Agreement, tobacco control programmes and cigarette excise taxes. Tob Control 2006;15:458-63.

18 Snyder KM. Tobacco price promotion: local regulation of discount coupons and certain value-added sales. Boston, MA: Center of Public Health and Tobacco Policy, 2013. http://www.tobaccopolicycenter.org/documents/TR-COUPON\%20FINAL.pdf

19 Feighery E, Rogers T, Ribisl K. Tobacco control retail price manipulation strategy summit proceedings. Sacramento, CA: California Department of Health, California Tobacco Control Program, 2009.

20 Hyland $\mathrm{A}$, Bauer JE, Li Q, et al. Higher cigarette prices influence cigarette purchase patterns. Tob Control 2005;14:86-92.

21 Hyland A, Higbee C, Bauer JE, et al. Cigarette purchasing behaviors when prices are high. J Public Health Manag Pract 2004;10:497-500.

22 White VM, White MM, Freeman K, et al. Cigarette promotional offers: who takes advantage? Am J Prev Med 2006:30:225-31.

23 Mecredy GC, Diemert LM, Callaghan RC, et al. Association between use of contraband tobacco and smoking cessation outcomes: a population-based cohort study. CMAJ 2013;185:E287-94.

24 Harding M, Leibtag E, Lovenheim MF. The heterogeneous geographic and socioeconomic incidence of cigarette taxes: evidence from nielsen homescan data. Am Econ J Econ Policy 2012;4:169-98.

25 Chaloupka FJ, Yurekli A, Fong GT. Tobacco taxes as a tobacco control strategy. Tob Control 2012;21:172-80.

26 Hyland A, Higbee C, Li Q, et al. Access to low-taxed cigarettes deters smoking cessation attempts. Am J Public Health 2005;95:994-5. 